한국농림기상학회지, 제16권 제1호(2014) (pISSN 1229-5671, eISSN 2288-1859)

Korean Journal of Agricultural and Forest Meteorology, Vol. 16, No. 1, (2014), pp. 11 21

DOI: 10.5532/KJAFM.2014.16.1.11

(C) Author(s) 2014. CC Attribution 3.0 License.

\author{
강화도 마니산 산림식생의 군집구조 특성 \\ 신학섭 ${ }^{1} \cdot$ 신재권 $^{2} \cdot$ 김혜진 ${ }^{3 *} \cdot$ 한상학 $^{3} \cdot$ 이원희 $^{3} \cdot$ 윤충원 $^{3}$ \\ 1국립생태원 기후생태연구실, ${ }^{2}$ 국립수목원 산림자원보존과, ${ }^{3}$ 국립공주대학교 산림자원학과 \\ (2014년 1월 9일 접수; 2014년 2월 13일 수정; 2014년 2월 19일 수락)
}

\title{
Characteristics of Community Structure for Forest Vegetation on Manisan, Ganghwado
}

\author{
Hak-Sub Shin ${ }^{1}$, Jae-Kwon Shin ${ }^{2}$, Hye-Jin Kim ${ }^{3 *}$, Sang-Hak Han ${ }^{3}$, \\ Won-Hee Lee $^{3}$ and Chung-Weon Yun ${ }^{3}$ \\ ${ }^{1}$ Department of Climate \& Ecology, National Institute of Korea, Seochon 325-810, Korea \\ ${ }^{2}$ Department of forest conservation, Korea National Arboretum, Pocheon 487-821, Korea \\ ${ }^{3}$ Department of Forest Resources, Kongju National University, Yesan 340-702, Korea \\ (Received January 9, 2014; Revised February 13, 2014; Accepted February 19, 2014)
}

\begin{abstract}
The purpose of this study was to furnish basic information for forest community ecology and to accumulate vegetational datum related to hierarchy of forest community for the efficient management of forest vegetation in Mt. Mani. Samples were collected and analyzed by 32 releves from August to October in 2010 using phytosociological analysis methodology of Z-M school and importance value analysis. The results were summarized that the forest vegetation was classified into 5 units in total. Importance value at vegetation unit 1 indicated Pinus densiflora $54.31(18.10 \%)$, Quercus mongolica 39.21 (13.07\%), Carpinus coreana 37.29 (12.43\%), at vegetation unit 2 Quercus mongolica 89.43 (22.23\%), Rhododendron mucronulatum 57.75 (14.43\%), Carpinus coreana 47.19(11.80\%), at vegetation unit 3 Styrax japonica 53.97 (13.50\%), Acer mono 33.60 (8.40\%), Carpinus coreana 26.48 (6.62\%), Quercus serrata 22.51 (5.64\%), at vegetation unit 4 Carpinus coreana 47.70 (11.92\%), Quercus acutissima 38.40 (9.60\%) and at vegetation unit 5 Evodia daniellii 80.59 (20.14\%), Robinia pseudoacacia $35.00(8.74 \%)$, Pueraria thunbergiana 28.63 (7.15\%), Quercus dentata 28.20 (7.05\%) in the order, respectively.
\end{abstract}

Key words: Forest community, Vegetation unit, Plant sociology, Importance value

\section{I. 서 론}

생물다양성은 육상생태계, 수생태계와 이들의 복합 생태계를 포함하는 모든 원천에서 발생한 생물체의 다 양성을 말하며, 종내종간 및 생태계의 다양성을 포함 한다(Kim, 2006). 생물다양성의 개념에는 종 다양성, 유전 다양성, 생태계 다양성을 총체적으로 포함한다 (SAF, 1991; Shin, 1995). 생물다양성 감소의 원인으
로는 서식면적의 감소와 파편화, 외래종의 이입, 과도 한 동식물의 채취, 각종 환경오염, 기후변화 등이 있 으며, 현재도 각종 개발로 인한 녹지의 파편화와 단절 로 인한 생물서식공간의 파괴, 개체군 고립, 인위적 교란으로 인한 생물종다양성 감소(Harris, 1984; Wilcox and Murphy, 1985)가 지속적인 문제가 되고 있다. 산림생태계의 종 다양성은 생물군집의 속성을 간접적으로 해석하는데 유익한 정보로서 활용될 수 있 
다(Kim et al., 2012). 여러 가지 생물종이 어우러져 구성된 생물군집은 종간 상호작용이 다양할 것이므로 종다양성이 높은 군집은 구조적으로 복잡할 것이다. 따라서 종간 상호작용이 관여하는 에너지 흐름, 먹이 사슬 구조, 생태적 지위(niche)구성에 있어서 종다양성 이 높은 군집일수록 보다 복잡하고 안정되며 성숙하였 다고 볼 수 있다(Kim et al., 1999).

산림식생(forest vegetation)의 분류는 그 분류의 목 적에 따라 전통적인(classical) 방법과 수리적인 (numerical) 방법을 구분 적용할 수 있다. 특수한 목 적이나 보편타당한 목적으로 나눌 수도 있으며, 식생 의 연속체(continuum)나 불연속체(discontinuum)의 논 점으로 나누어 접근할 수도 있다. 자연성의 정도에 따 른 접근 등 자료분석을 위한 접근방법이 매우 다양하 여(Mucina, 1997), 식물사회학적 식생조사와 분석은 대상으로 하는 산림식생의 분류목적에 따라 그 가치와 방향 및 접근방식에 상당한 차이를 나타내고 있다. 현 재 인천광역시 강화도 마니산의 경우 환경부의 식물상 에 관한 연구(Ministry of Environment, 1999)와 마 니산과 강화도 일대의 식생에 관한 연구(Kang, 1969) 등, 강화도 간척지 부근식물의 분류학적 연구를 다룬 자연과학논문들이 일부 있으나 마니산 산림식생의 군 락구조에 대하여 군락별 구분종(differential species)과 군락단위별 중요치를 중심으로 종조성적 측면에서 접 근한 연구는 거의 없는 실정이다. 이에 본 연구는 마 니산 산림식생의 식물사회학적 식생유형을 기초로 군 집수준에서 마니산의 현존식생을 파악하고, 식생군집 구조를 규명하여 마니산의 산림식생 관리에서 군집단 위의 종 조성 바탕의 산림식생관리의 기초자료 제공을 목적으로 수행하였다.

\section{II. 재료 및 방법}

\section{1. 조사지 개황}

마니산 일대(동경 $126^{\circ} 21^{\prime} 126^{\circ} 32^{\prime}$, 북위 $37^{\circ} 35^{\prime}$ $37^{\circ} 45^{\prime}$ )는 행정구역상 인천광역시 강화군 화도면 덕포 리, 동막리, 사기리, 문산리 등 일원에 속하며 (Ministry of Environment, 1999), 마니산은 해발 $469.4 \mathrm{~m}$ 로 세 봉우리가 있고, 첨성단은 그 중간 봉우 리에 위치하고 있다. 참성단은 단군왕검이 하늘에 제 를 올렸다는 곳으로 알려져 있으며, 마니산 정상에서 남쪽으로는 서해의 여러 섬이 보이고, 맑은 날에는 북

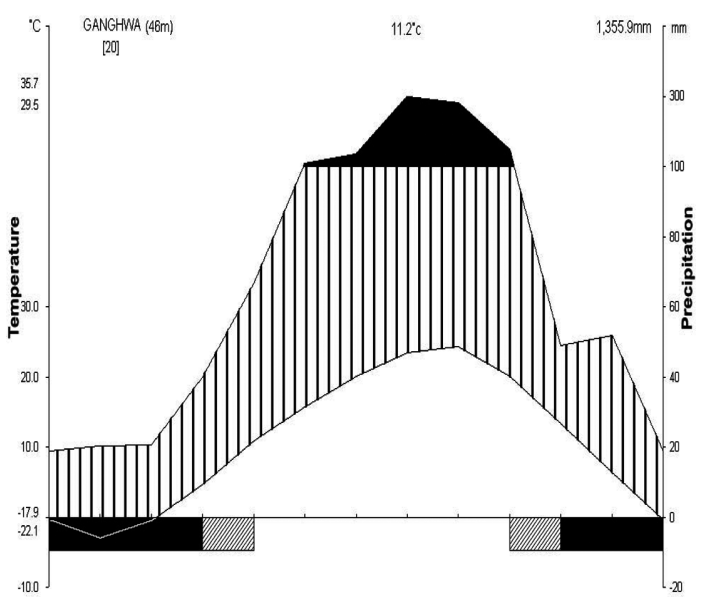

Fig. 1. Climate diagram of Ganghwa near the study area.

쪽으로 개성의 송악산이 보인다(http://www.ganghwa. incheon.kr). 식생은 상관적으로 소사나무림이 독특하게 능선부 일대에 분포하고 있으며, 사면부에는 개서어나 무림이, 사면중하부에는 밤나무, 아까시나무 등이 각각 혼효되어 있고, 마을 인근에는 쉬나무, 상수리나무, 밤나 무 등이 점유하고 있었다.

마니산의 기상자료는 조사지역과 인접한 강화기상관 측소의 최근 20년간(1989-2008년) 기상자료를 이용하 여 Climate diagram을 작성하였다(Walter, 1979). 기 상자료에 의하면 강화도의 연평균기온은 $11.2^{\circ} \mathrm{C}$, 연평 균강수량은 $1,355.9 \mathrm{~mm}$ 이며, 절대최저기온은 $-22.1^{\circ} \mathrm{C}$, 절대최고기온은 $35.7^{\circ} \mathrm{C}$, 가장 추운 달인 1 월의 일평 균 최저기온은 $-17.9^{\circ} \mathrm{C}$, 가장 더운 달인 8 월의 일평 균 최고기온은 $29.5^{\circ} \mathrm{C}$ 로 나타났다(Fig. 1).

\section{2. 조사 및 분석방법}

마니산의 산림식생을 대상으로 2010년 8월부터 2010년 10월 마니산 일대의 전반적인 식생개황과 지 형지세를 파악한 후, 총 32 개소 $(10 \mathrm{~m} \times 10 \mathrm{~m}, 20 \mathrm{~m} \times 20 \mathrm{~m})$ 의 방형구를 현장 여건에 맞게 설치하여 식물사회학적 방법(Ellenberg, 1956; Braun-Blanquet, 1964)에 따라 지형, 생태적 밀도, 해발 등의 여러 입지 환경 요인을 고려하였으며, 식생조사법에 따라 조사구내에 출현하 는 각 종의 피도와 개체수를 조합시킨 우점도계급을 층위별로 구분하여 판정 기록하였고, 생육상태는 종 개체의 집합 혹은 이산의 정도에 따른 군도계급 등을 측정하여 식생조사를 수행하였고(Fig. 2), 식물종의 동 정은 대한식물도감(Lee, 2003), 원색한국식물도감(Lee, 


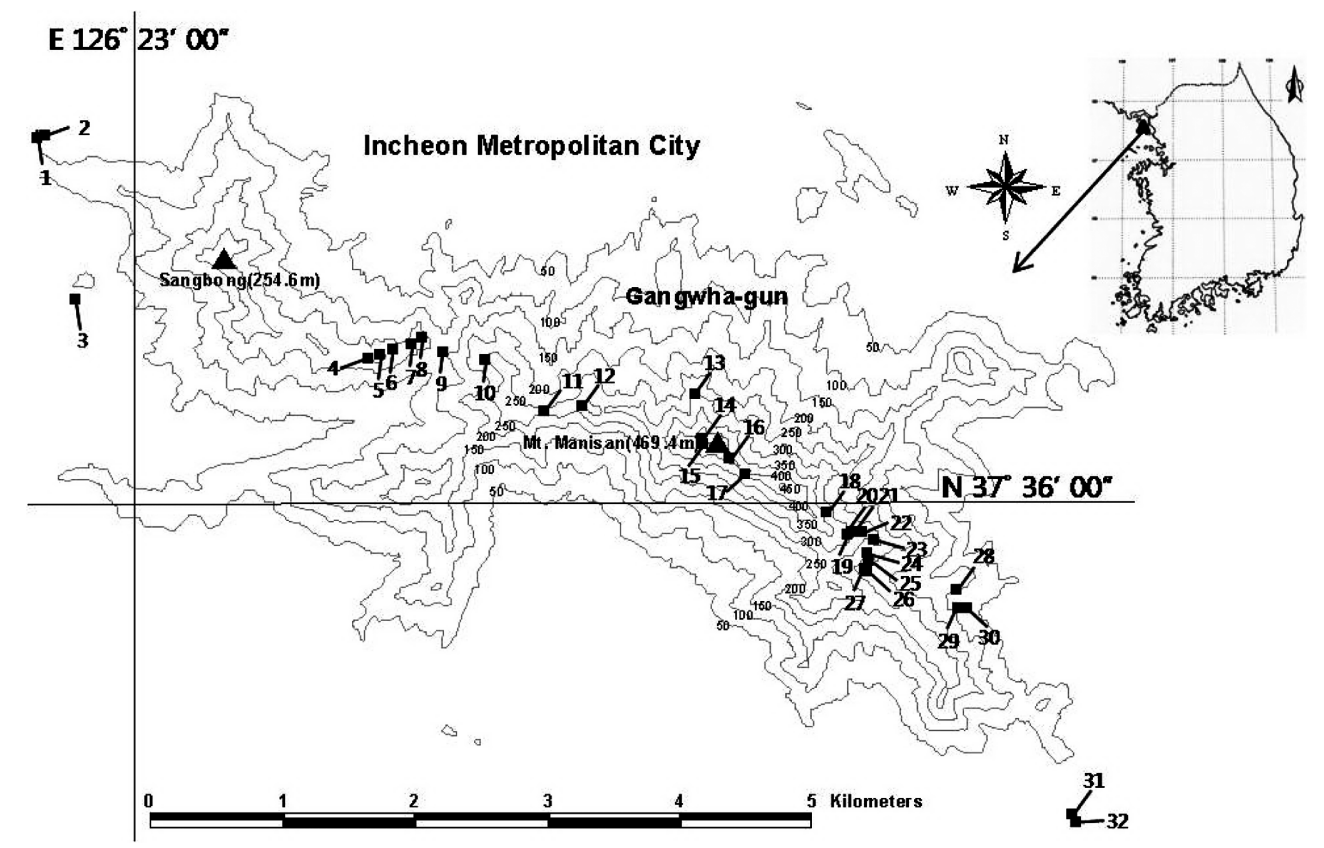

Fig. 2. Location of study site in Mt. Mani.

2004), 국립수목원(http://www.kna.go.kr)을 참고하였다 . 식물사회학적 방법으로 조사된 우점도 계급을 우점도 범위의 중앙치로 환산한 상대우점도(Dierssen, 1990)와 상대빈도의 평균값으로 중요치를 구하였다. 중요치는 층위별 종의 점유정도를 정량적으로 파악할 수 있고, 또한 군락별 종(種) 조성 비교에도 유효하므로 식생단 위와 층위를 각각 구분하여 종 조성에 근간을 둔 표 조작 방법에 의해 작성된 식별표(상재도표) 상의 식생 단위마다 각각 중요치를 산출하였다.

\section{III. 결과 및 고찰}

\section{1. 식생유형과 종구성}

본 조사지인 마니산에서 얻어진 32 개소의 식생자료 를 토대로 Z-M식물사회학적 방법에 의해 산림식생유 형 분류를 수행하였던 바, 마니산의 산림식생유형은 소사나무, 생강나무, 팥배나무, 물푸레나무, 산딸나무, 대사초를 표징종으로 하는 소사나무군락과 쉬나무, 병 아리꽃나무, 줄사철나무, 줄딸기, 장구밥나무, 명아주를 식별종 및 표징종으로 하는 쉬나무군락으로 크게 분류 되었고, 소사나무군락은 신갈나무, 진달래, 맑은대쑥, 산거울을 식별종으로 하는 신갈나무군과 때죽나무, 밤
나무, 고로쇠나무, 상수리나무, 쪽동백나무, 주름조개풀, 천남성을 식별종으로 하는 때죽나무군의 2 개 군으로 세분되었다. 신갈나무군은 다시 소나무를 식별종으로 하는 소나무소군과 덜껑나무, 실새풀, 가는잎족제비고 사리, 고깔제비꽃, 삽주를 식별종으로 하는 덜꿩나무소 군으로, 때죽나무군은 굴참나무, 비목나무, 작살나무 등 을 식별종으로 하는 굴참나무소군과 때죽나무전형소군 으로 세분되었다. 한편 식별표에서 담쟁이덩굴, 칡, 아 까시나무 등을 식별종으로 하는 담쟁이덩굴종군은 식 생단위와는 별도로 앞으로 종군들의 체계화에 활용될 가능성이 높은 것으로 사료되었다. 따라서 마니산의 산림식생은 여러 종군들의 구분에 의해 2 개 군락, 2 개 군, 4 개 소군으로 분류되었고, 또한 환경인자들의 총화 로 결정되어진 것으로 사료되는 식생유형은 총 5 개로 나타닜다(Table 1).

우리나라 대부분의 산림식생 유형체계는 종군개념에 서 가장 상위 단위에 신갈나무종군이 나타나는 반면에 (Yun et al., 2011; Song and Yun, 2006; Lee et al., 2005; Cho et al., 2004; Lee and Yun, 2002; Lee et al., 2001; Lee, 2000; Song et al., 1999; Lee et al., 1999; Oh et al., 1998), 본 조사지인 마니산의 산림 식생은 소사나무군락 하위단위로 신갈나무가 나타났다 
Table 1. Differentiated constancy table of forest vegetation in the Mt. Mani

\begin{tabular}{|c|c|c|c|c|c|}
\hline $\begin{array}{c}\text { Vegetation unit } \\
\text { Altitude }(\mathrm{m}) \\
\text { Slope degree }\left({ }^{\circ} \mathrm{C}\right) \\
\text { Bare rock }(\%) \\
\text { Coverage of tree layer(\%) } \\
\text { Hight of tree layer(m) } \\
\text { DBH(Diameter at Breast Height) of tree layer }(\mathrm{cm}) \\
\text { The number of present species } \\
\text { Releve }\end{array}$ & $\begin{array}{c}1 \\
295 \\
27 \\
18 \\
89 \\
5 \\
9 \\
14 \\
4\end{array}$ & $\begin{array}{c}2 \\
294 \\
26 \\
15 \\
90 \\
7 \\
15 \\
16 \\
10\end{array}$ & $\begin{array}{c}3 \\
150 \\
12 \\
31 \\
82 \\
12 \\
25 \\
18 \\
10\end{array}$ & $\begin{array}{c}4 \\
166 \\
13 \\
3 \\
73 \\
11 \\
24 \\
23 \\
6\end{array}$ & $\begin{array}{c}5 \\
26 \\
45 \\
33 \\
55 \\
12 \\
25 \\
29 \\
2\end{array}$ \\
\hline \multicolumn{6}{|c|}{ 1. Character and differential species of Carpinus coreana community ; } \\
\hline $\begin{array}{l}\text { Carpinus coreana } \\
\text { Lindera obtusiloba } \\
\text { Sorbus alnifolia } \\
\text { Fraxinus rhynchophylla } \\
\text { Cornus kousa } \\
\text { Carex siderosticta }\end{array}$ & $\begin{array}{l}214 \\
2++ \\
122 \\
2+1 \\
2+1 \\
1++\end{array}$ & $\begin{array}{l}\text { IV+5 } \\
\text { IV+1 } \\
\text { IV12 } \\
\text { III+1 } \\
\text { III+3 } \\
\text { II+2 }\end{array}$ & $\begin{array}{l}\text { III15 } \\
\text { IV+1 } \\
\text { III+2 } \\
\text { III+1 } \\
\text { II } 22 \\
\text { II+1 }\end{array}$ & $\begin{array}{c}\text { IV15 } \\
\text { IV }+2 \\
\text { I33 } \\
\text { II }+1 \\
\text { I11 } \\
\text { I++ }\end{array}$ & $\begin{array}{c}144 \\
- \\
1++ \\
- \\
- \\
-\end{array}$ \\
\hline
\end{tabular}

2. Character and differential species of Evodia daniellii community ;

Evodia daniellii

Chenopodium album var. centrorubrum

Rhodotypos scandens

Euonymus fortunei var. radicans

Rubus oldhami

Grewia biloba var. parviflora

3. Differential species of Quercus mongolica group ;

\section{Ouercus mongolica \\ Rhododendron mucronulatum \\ Artemisia keiskeana \\ Carex humilis}

Pinus densiflora

Viburnum erosum

Calamagrostis arundinacea

Dryopteris chinensis

Viola rossii

Atractylodes japonica

Styrax japonica

Castanea crenata

Acer mono

Quercus acutissima

Styrax obassia

Oplismenus undulatifolius

Arisaema amurense var. serratum

Quercus variabili

Lindera erythrocarpa

Callicarpa japonica

Dryopteris lacera

Hepatica asiatica

Parthenocissus tricuspidata

Pueraria thunbergiana

Robinia pseudo-acacia

Quercus aliena

Smilax sieboldi

Commelina communis

Quercus dentata

Symplocos chinensis for. pilosa

Spodiopogon sibiricus

Quercus serrata

Asarum sieboldii

Disporum smilacinum
Smilax riparia var. ussuriensis

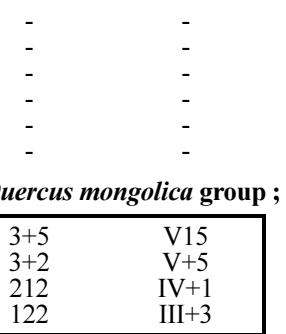

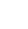

(n)

\begin{tabular}{l|l|}
- & 214 \\
- & $2++$ \\
- & 211 \\
- & 211 \\
- & $2+1$ \\
- & 133 \\
\hline
\end{tabular}

$\begin{array}{ccc}3+5 & \text { V15 } \\ 3+2 & \text { V }+5\end{array}$

$\begin{array}{ccc}- & - & - \\ \mathrm{I}+1 & \mathrm{II} 11 & - \\ - & - & - \\ \mathrm{I}++ & - & -\end{array}$

4. Differential species of Pinus densiflora subgroup ;

\begin{tabular}{|c|}
\hline 415 \\
of Viburnum erosum subgroup ;
\end{tabular}

5. Differential species of Viburnum erosum subgroup ;

I11 II1

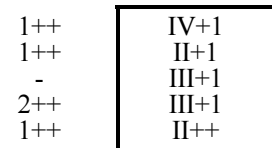

6. Differential species of Styrax japonica group;

\begin{tabular}{cc|cc|}
\cline { 3 - 4 } $1++$ & I++ & V14 & IVr1 \\
- & - & III14 & III12 \\
- & - & IV+4 & III+1 \\
- & - & I45 & II55 \\
$1++$ & I+1 & III12 & II+2 \\
$2 r+$ & - & IV+2 & V+1 \\
- & - & I++ & IIr+ \\
\hline
\end{tabular}

7. Differential species of Quercus variabilis subgroup ;

$\begin{array}{ccc}\mathrm{I}+1 & \mathrm{I}++ & - \\ \mathrm{I}++ & - & - \\ \mathrm{I}++ & \mathrm{I}++ & - \\ \mathrm{I}++ & - & - \\ - & - & -\end{array}$

*Other 116 companion species among total of 164 species omitted.

\begin{tabular}{cc|c|}
- & I11 & III14 \\
- & I++ & III+2 \\
- & - & II+1 \\
- & - & I11 \\
- & - & Ir+ \\
\hline
\end{tabular}

8. Differential species group of Parthenocissus tricuspidata ;

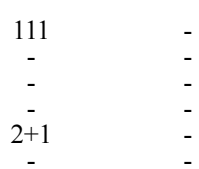

\begin{tabular}{c|cc|}
\cline { 2 - 3 } $\mathrm{I}+2$ & V24 & 211 \\
- & V+1 & 133 \\
- & IIr1 & 212 \\
- & II11 & 111 \\
- & III++ & $1++$ \\
I++ & III+1 & 211 \\
\hline
\end{tabular}

9. Companion species group ;

$\begin{array}{cc}2++ & \text { I11 } \\ 212 & \text { II11 } \\ 212 & \text { II+1 } \\ 2+1 & \text { I15 } \\ - & \text { IIIr+ } \\ 1++ & \text { III }+2 \\ 111 & \text { II }++\end{array}$

$\begin{array}{ccc}\text { I+1 } & \text { III12 } & 122 \\ \text { I+1 } & \text { I++ } & - \\ - & \text { I++ } & 2++ \\ \text { II } 45 & - & - \\ \text { III++ } & \text { I11 } & - \\ \text { II++ } & - & - \\ \text { III+4 } & - & -\end{array}$


Table 2. Importance value of major species at vegetation unit 1

\begin{tabular}{lccccc}
\hline \hline \multicolumn{1}{c}{ Scientific name } & Tree & Subtree & Shrub & Herb & Total(\%) \\
\hline Pinus densiflora & 54.31 & - & - & - & $54.31(18.10)$ \\
Quercus mongolica & 23.44 & - & 5.30 & 10.47 & $39.21(13.07)$ \\
Carpinus coreana & 5.70 & - & 28.46 & 3.13 & $37.29(12.43)$ \\
Cornus kousa & 5.70 & - & 7.77 & 1.52 & $14.99(5.00)$ \\
Quercus serrata & 5.70 & - & - & 1.52 & $7.22(2.41)$ \\
Juniperus rigida & 5.13 & - & - & - & $5.13(1.71)$ \\
Rhododendron mucronulatum & - & - & 18.11 & 3.04 & $21.16(7.05)$ \\
Symplocos chinensis for.pilosa & - & - & 14.35 & - & $14.35(4.78)$ \\
Fraxinus rhynchophylla & - & - & 9.18 & 3.04 & $12.22(4.07)$ \\
Sorbus alnifolia & - & - & 9.06 & - & $9.06(3.02)$ \\
Quercus dentata & - & - & 3.88 & 1.52 & $5.41(1.80)$ \\
Rhus sylvestris & - & - & 3.88 & - & $3.88(1.29)$ \\
Artemisia keiskeana & - & - & - & 10.56 & $10.56(3.52)$ \\
Spodiopogon sibiricus & - & - & - & 10.56 & $10.56(3.52)$ \\
Carex humilis & - & - & - & 7.43 & $7.44(2.48)$ \\
Other 23 species & - & - & - & 47.21 & $47.21(15.75)$ \\
\hline \multicolumn{1}{c}{ Total } & 100 & - & 100 & 100 & $300(100)$ \\
\hline
\end{tabular}

는 것이 특징이었다. 이는 서해안 강화도의 마니산 능 선부에 우점적으로 분포하는 소사나무림 때문일 것으 로 사료되었다.

\section{2. 중요치}

\subsection{1. 식생단위 1 (소사나무군락-신갈나무군-소나무소}

\section{군; 조사구수 4)}

본 식생단위는 소사나무군락에서 종군 3의 신갈나무, 진달래, 맑은대쑥, 산거울의 식별종 출현으로 신갈나무 군으로 분류되었고, 신갈나무군은 다시 종군 4의 소나 무 식별종 출현에 의해 소나무소군으로 세분된 단위이 다. 총 조사구는 4 개소로 입지환경요인들 중 평균해발 고는 $295 \mathrm{~m}(204 \mathrm{~m}-421 \mathrm{~m})$, 지형은 사면상부에 집중되 었고, 출현종수는 14 종으로 전체 식생단위 중에서 가 장 낮았다. 교목층 평균수고는 $5 \mathrm{~m}(4 \mathrm{~m}-5 \mathrm{~m})$, 평균흥 고직경은 $9 \mathrm{~cm}(6 \mathrm{~cm}-12 \mathrm{~cm})$ 로 가장 5 개 식생단위 중 에서 가장 작은 것으로 나타났다(Table 1).

식생단위 1 의 중요치는 소나무 $54.31(18.10 \%)$, 신 갈나무 39.21 (13.07\%), 소사나무37.29 (12.43\%), 진 달래 21.16 (7.05\%), 산딸나무 14.99 (5.00\%), 노린 재나무 14.35 (4.78\%), 물푸레나무 12.22 (4.07\%) 순으로 중요치가 높게 나타났다. 교목층에는 소나무의 중요치가 54.31, 신갈나무 23.44 , 소사나무 5.70의 순
으로 중요치가 나타났으며, 관목층의 중요치는 소사나 무가 28.46, 진달래 18.11 , 노린재나무 14.34 의 순으로 높게 나타났고, 초본층의 중요치는 큰기름새, 산거울이 각각 10.56 , 신갈나무가 10.47 순으로 나타났다(Table 2). 교목층에서 소나무의 중요치가 54.31로 높았지만 아교목층 이하에서는 전혀 출현하지 않았고, 신갈나무 는 교목층, 관목층, 초본층에서 각각 $23.44,5.30$, 10.47 로 나타나 전반적으로 모든 층위에서 출현하고 있 었다. 소사나무는 관목층, 교목층, 초본층에서 각각 $28.46,5.70,3.13$ 로 나타나 관목층의 중요치가 가장 높은 것으로 나타났다. 이는 본 식생단위의 잠재식생 이 소사나무림이 될 수도 있을 것으로 사료되었다.

\subsection{2. 식생단위 2(소사나무군락-신갈나무군-덜꼉나무} 소군; 조사구수 10)

본 식생단위는 소사나무군락의 신갈나무군에서 종군 5의 덜꿩나무, 실새풀, 가는잎족제비고사리, 고깔제비꽃, 삽주의 식별종에 의해 분류된 덜꿩나무소군이다. 덜낑 나무소군에서 덜뀡나무의 상재도는 등급으로 높게 나 타났고, 총 조사구수는 10 개소이며, 입지환경은 평균해 발고가 $294 \mathrm{~m}(202 \mathrm{~m}-400 \mathrm{~m})$, 평균경사도는 $26^{\circ}\left(10^{\circ}-\right.$ $\left.45^{\circ}\right)$, 사면상부의 지형에 주로 분포하고 있었다. 관목 층의 평균식피율은 $66 \%(30 \%-90 \%)$ 로 전체 식생단위 
Table 3. Importance value of major species at vegetation unit 2

\begin{tabular}{lccccc}
\hline \hline & \multicolumn{5}{c}{ Layer } \\
\hline \multicolumn{1}{c}{ Scientific name } & Tree & Subtree & Shrub & Herb & Total(\%) \\
\hline Quercus mongolica & 56.49 & 22.32 & 4.62 & 6.00 & $89.43(22.36)$ \\
Carpinus coreana & 14.06 & 25.24 & 6.71 & 1.17 & $47.19(11.80)$ \\
Sorbus alnifolia & 11.44 & 12.97 & 2.42 & 0.59 & $27.41(6.85)$ \\
Quercus serrata & 6.57 & 3.61 & 1.54 & 1.85 & $13.58(3.39)$ \\
Prunus leveilleana & 4.58 & - & - & - & $4.58(1.14)$ \\
Quercus variabilis & 2.29 & 2.81 & - & - & $5.10(1.27)$ \\
Quercus dentata & 2.29 & - & - & - & $2.29(0.57)$ \\
Carpinus tschonoskii & 2.29 & - & - & - & $2.29(0.57)$ \\
Cornus kousa & - & 22.22 & 1.54 & 0.59 & $24.33(6.08)$ \\
Rhododendron mucronulatum & - & 3.61 & 48.61 & 5.55 & $57.75(14.43)$ \\
Carpinus cordata & - & 3.61 & 5.50 & 1.26 & $10.38(2.59)$ \\
Fraxinus rhynchophylla & - & 3.61 & 3.63 & 1.17 & $8.41(2.10)$ \\
Symplocos chinensis & - & - & 6.16 & - & $6.16(1.54)$ \\
Lindera obtusiloba & - & - & 5.50 & 1.76 & $7.24(1.80)$ \\
Viburnum erosum & - & - & 5.17 & 4.78 & $9.95(2.49)$ \\
Euonymus oxyphyllus & - & - & 3.08 & - & $3.08(0.77)$ \\
Styrax obassia & - & - & 1.54 & 1.17 & $2.71(0.68)$ \\
Stephanandra incisa & - & - & 1.54 & 1.17 & $2.71(0.68)$ \\
Rhus trichocarpa & - & - & 1.21 & 0.59 & $1.80(0.45)$ \\
Pourthiaea villosa & - & - & 1.21 & - & $1.21(0.30)$ \\
Carex humilis & - & - & - & 10.92 & $10.92(2.73)$ \\
Smilax riparia & - & - & - & 6.78 & $6.78(1.69)$ \\
Carex siderosticta & - & - & - & 5.51 & $5.51(1.38)$ \\
Other 30 species & Total & 100 & 100 & 100 & $400(100)$ \\
\hline
\end{tabular}

중에서 가장 높게 나타났다.

식생단위 2의 중요치는 신갈나무 89.43 (22.23\%), 진달래 57.75 (14.43\%), 소사나무 47.19 (11.80\%), 팥배나무 27.41(6.85\%), 산딸나무 24.33 (6.08\%), 졸 참나무 13.58 (3.39\%), 산거울 10.92 (2.73\%) 순으 로 높게 나타났다. 교목층에는 신갈나무의 중요치가 56.49 , 소사나무 14.06 , 핕배나무 11.44 의 순으로 나 타났으며, 아교목층에는 소사나무 25.24, 신갈나무 22.32 , 산딸나무 22.22 의 순으로 나타났다. 관목층에서 는 진달래의 중요치가 48.61로 가장 높았고, 소사나무 6.71 , 생강나무 6.16 의 순으로 나타났으며, 초본층에는 산거울 10.92 , 밀나물 6.78 , 신갈나무 6.00 순으로 나 타났다. 신갈나무의 중요치는 교목층, 아교목층, 관목 층, 초본층에 각각 $56.49,22.32,4.62,6.00$ 으로 모 든 층위에서 높게 나타나고 있었고, 소사나무는 교목 층, 아교목층, 관목층, 초본층에 각각 $14.06,25.24$, $6.71,1.17$ 로서 아교목층이 가장 높게 나타났다. 진달
래는 아교목층, 관목층, 초본층에서 각각 $3.61,48.61$, 5.55 로 관목층의 점유율이 매우 높게 나타났고, 덜뀡나 무는 교목층, 아교목층에서 나타나지 않았고, 관목층과 초본층에서만 출현하였는데 중요치는 각각 $5.17,4.78$ 로 나타났다(Table 3).

\subsection{3. 식생단위 3(소사나무군락-때죽나무군-굴참나무 소군; 조사구수 10)}

본 식생단위는 소사나무군락에서 종군 6 의 때죽나무, 밤나무, 고로쇠나무, 상수리나무, 쪽동백나무, 주름조개 풀, 천남성의 식별종 출현으로 때죽나무군으로 분류되 었고, 때죽나무군은 다시 종군 7의 굴참나무, 비목나무, 작살나무, 비늘고사리, 노루귀의 식별종 출현에 의해 세분된 굴참나무소군의 단위이다. 입지환경요인들 중 평균경사도는 $12^{\circ}\left(5^{\circ}-20^{\circ}\right)$ 로 5 개 식생단위 중에서 가 장 낮게 나타났으며, 평균노암율은 $31 \%(1 \%-60 \%)$ 로 두 번째로 높았으며, 교목층의 평균수고와 평균흥고직 
경은 각각 $12 \mathrm{~m}, 25 \mathrm{~cm}$ 로 나타났고, 관목층의 식피율 은 $29 \%$ 로 가장 낮게 나타났다.

본 식생단위의 중요치는 때죽나무 53.97 (13.50\%), 고로쇠나무 $33.60(8.40 \%)$, 소사나무 26.48 (6.62\%), 졸참나무 22.51 (5.64\%), 애기나리 17.98 (4.50\%), 밤나무 17.92 (4.48\%), 굴참나무 17.35 (4.34\%) 순
으로 중요치가 높게 나타났다. 교목층에는 졸참나무의 중요치가 17.73 , 굴참나무 17.35 , 밤나무 15.76 , 상수 리나무 12.30 의 순으로 높게 나타났으며, 주요 참나무 과 수종(졸참나무, 굴참나무, 밤나무, 상수리나무)의 중 요치가 12.00 이상으로 높게 나타난 것이 특징적이었다. 아교목층에서는 때죽나무의 중요치가 30.19 로 가장 높

Table 4. Importance value of major species at vegetation unit 3

\begin{tabular}{|c|c|c|c|c|c|}
\hline \multicolumn{6}{|c|}{ Layer } \\
\hline Scientific name & Tree & Subtree & Shrub & Herb & Total $(\%)$ \\
\hline Quercus serrata & 17.73 & 4.78 & - & - & $22.51(5.64)$ \\
\hline Quercus variabilis & 17.35 & - & - & - & $17.35(4.34)$ \\
\hline Castanea crenata & 15.76 & 1.55 & - & 0.61 & $17.92(4.48)$ \\
\hline Quercus acutissima & 12.30 & - & - & - & $12.30(3.08)$ \\
\hline Carpinus coreana & 8.98 & 14.62 & 2.26 & 0.61 & $26.48(6.62)$ \\
\hline Acer pictum & 7.53 & 9.11 & 15.11 & 1.84 & $33.60(8.40)$ \\
\hline Styrax japonica & 4.91 & 30.19 & 18.25 & 0.61 & $53.97(13.50)$ \\
\hline Zelkova serrata & 2.80 & 1.55 & - & - & $4.36(1.09)$ \\
\hline Fraxinus rhynchophylla & 2.11 & 1.55 & 2.26 & 1.84 & $7.76(1.94)$ \\
\hline Prunus leveilleana & 2.11 & 1.23 & 1.39 & - & 4.73(1.18) \\
\hline Quercus dentata & 2.11 & - & 1.39 & 0.61 & $4.11(1.03)$ \\
\hline Tilia taquetii & 2.11 & - & - & 0.61 & $2.72(0.68)$ \\
\hline Pinus densiflora & 2.11 & - & - & - & $2.11(0.53)$ \\
\hline Tilia amurensis & 2.11 & - & - & - & $2.11(0.53)$ \\
\hline Styrax obassia & - & 9.42 & - & - & $9.43(2.36)$ \\
\hline Cornus kousa & - & 7.17 & - & - & $7.17(1.79)$ \\
\hline Sorbus alnifolia & - & 5.49 & 5.91 & - & $11.40(2.85)$ \\
\hline Carpinus cordata & - & 3.94 & 9.13 & 0.61 & $13.68(3.42)$ \\
\hline Carpinus tschonoskii & - & 2.39 & 4.60 & 1.30 & $8.29(2.07)$ \\
\hline Lindera erythrocarpa & - & 2.39 & 4.53 & 2.53 & $9.45(2.36)$ \\
\hline Lindera obtusiloba & - & 1.55 & 5.03 & 2.46 & $9.04(2.26)$ \\
\hline Picrasma quassioides & - & 1.55 & - & - & $1.55(0.39)$ \\
\hline Hovenia dulcis & - & 1.55 & - & - & $1.55(0.39)$ \\
\hline Lonicera praeflorens & - & - & 4.60 & - & $4.60(1.15)$ \\
\hline Stephanandra incisa & - & - & 4.53 & 3.14 & $7.67(1.92)$ \\
\hline Callicarpa japonica & - & - & 3.65 & 1.23 & $4.88(1.22)$ \\
\hline Ligustrum obtusifolium & - & - & 3.65 & 0.61 & $4.27(1.07)$ \\
\hline Rhododendron mucronulatum & - & - & 3.65 & - & $3.65(0.91)$ \\
\hline Viburnum erosum & - & - & 2.77 & 1.30 & $4.07(1.02)$ \\
\hline Zanthoxylum piperitum & - & - & 2.26 & 1.23 & $3.49(0.87)$ \\
\hline Symplocos chinensis & - & - & 2.26 & 0.61 & $2.88(0.72)$ \\
\hline Parthenocissus tricuspidata & - & - & 1.39 & 3.74 & $5.12(1.28)$ \\
\hline Pourthiaea villosa & - & - & 1.39 & - & $1.39(0.35)$ \\
\hline Disporum smilacinum & - & - & - & 17.98 & $17.98(4.50)$ \\
\hline Oplismenus undulatifolius & - & - & - & 13.20 & $13.20(3.30)$ \\
\hline Asarum sieboldii & - & - & - & 3.69 & $3.69(0.92)$ \\
\hline Other 37 species & - & - & - & 39.52 & $39.52(9.84)$ \\
\hline Total & 100 & 100 & 100 & 100 & $400(100)$ \\
\hline
\end{tabular}


게 나타났고, 소사나무, 쪽동백나무가 각각 14.62 , 9.42의 순으로 나타났다. 관목층에서의 중요치는 때죽 나무 18.25 , 고로쇠나무 15.11 , 까치박달 9.13의 순으 로 나타났고, 초본층에는 애기나리 17.98 , 주름조개풀 13.20 의 순으로 나타났다. 교목층에서 중요치가 굴참나 무 17.35 , 상수리나무 12.30 으로 높았지만, 아교목층 이하에서는 출현하지 않았고, 때죽나무는 아교목층 30.19 , 관목층 18.25 로 중요치가 가장 높게 나타나고 있었다. 소사나무는 교목층, 아교목층, 관목층, 초본층
에 각각 $8.98,14.62,2.26,0.61$ 로 전반적으로 모든 층위에서 출현하고 있었다(Table 4).

\subsection{4. 식생단위 4(소사나무군락-때죽나무군-때죽나무} 전형소군; 조사구수 6)

본 식생단위는 소사나무군락의 때죽나무군에서 종군 7 의 식별종들이 출현하지 않음으로 해서 분류된 때죽 나무전형소군으로 총 6 개소가 조사되었다. 입지환경요 인 중 평균노암율이 $3 \%(0 \%-10 \%)$ 로 전체 식생단위

Table 5. Importance value of major species at vegetation unit 4

\begin{tabular}{|c|c|c|c|c|c|}
\hline \multicolumn{6}{|c|}{ Layer } \\
\hline Scientific name & Tree & Subtree & Shrub & Herb & Total( $\%)$ \\
\hline Quercus acutissima & 25.60 & 12.31 & - & 0.48 & $38.40(9.60)$ \\
\hline Carpinus coreana & 16.95 & 12.31 & 17.46 & 0.97 & $47.70(11.92)$ \\
\hline Castanea crenata & 13.72 & - & - & 0.55 & $14.28(3.57)$ \\
\hline Tilia amurensis & 12.80 & - & - & 0.55 & $13.36(3.34)$ \\
\hline Ficus erecta & 10.16 & - & 9.38 & 4.47 & $24.01(6.00)$ \\
\hline Quercus dentata & 8.30 & - & 3.17 & 2.07 & $13.55(3.39)$ \\
\hline Pinus densiflora & 4.15 & 7.68 & - & - & $11.83(2.96)$ \\
\hline Quercus aliena & 4.15 & - & 3.17 & 0.97 & $8.30(2.07)$ \\
\hline Robinia pseudo-acacia & 4.15 & - & - & 0.48 & $4.64(1.16)$ \\
\hline Sorbus alnifolia & - & 20.03 & 3.17 & - & $23.21(5.80)$ \\
\hline Lindera obtusiloba & - & 12.31 & 9.52 & 1.52 & $23.36(5.84)$ \\
\hline Styrax obassia & - & 12.31 & 2.04 & 1.11 & $15.46(3.87)$ \\
\hline Styrax japonica & - & 7.68 & 9.52 & 0.48 & $17.69(4.42)$ \\
\hline Acer топо & - & 7.68 & - & 1.11 & $8.79(2.20)$ \\
\hline Prunus leveilleana & - & 7.68 & - & - & $7.68(1.92)$ \\
\hline Elaeagnus umbellata & - & - & 8.24 & - & $8.25(2.06)$ \\
\hline Zelkova serrata & - & - & 6.20 & - & $6.21(1.55)$ \\
\hline Cornus kousa & - & - & 3.17 & 0.97 & $4.15(1.04)$ \\
\hline Rhododendron mucronulatum & - & - & 3.17 & 0.97 & $4.15(1.04)$ \\
\hline Euonymus oxyphyllus & - & - & 3.17 & - & $3.18(0.79)$ \\
\hline Cudrania tricuspidata & - & - & 3.17 & - & $3.18(0.79)$ \\
\hline Acer ginnala & - & - & 3.17 & - & $3.18(0.79)$ \\
\hline Parthenocissus tricuspidata & - & - & 2.04 & 20.26 & $22.30(5.57)$ \\
\hline Zanthoxylum schinifolium & - & - & 2.04 & 0.55 & $2.59(0.65)$ \\
\hline Symplocos chinensis for pilosa & - & - & 2.04 & - & $2.04(0.51)$ \\
\hline Zanthoxylum piperitum & - & - & 2.04 & - & $2.04(0.51)$ \\
\hline Morus bombycis & - & - & 2.04 & - & $2.04(0.51)$ \\
\hline Euonymus alatus for. ciliato-dentatus & - & - & 2.04 & - & $2.04(0.51)$ \\
\hline Davallia mariesii & - & - & - & 3.91 & $3.92(0.98)$ \\
\hline Pilea peploides & - & - & - & 3.91 & $3.92(0.98)$ \\
\hline Oplismenus undulatifolius & - & - & - & 3.60 & $3.60(0.90)$ \\
\hline Pueraria thunbergiana & - & - & - & 3.19 & $3.19(0.80)$ \\
\hline Other 59 species & - & - & - & 47.76 & $47.76(11.96)$ \\
\hline Total & 100 & 100 & 100 & 100 & $400(100)$ \\
\hline
\end{tabular}


중에서 가장 낮게 나타났고, 아교목층의 평균식피율은 $22 \%(0 \%-55 \%)$ 로 가장 낮았으나, 초본층 평균식피율 은 $63 \%(45 \%-80 \%)$ 로 가장 높았으며, 대부분 사면 하부에 분포하고 있었다.

본 식생단위의 중요치는 소사나무 47.70 (11.92\%), 상수리나무 38.40 (9.60\%), 천선과나무 24.01 (6.00\%), 생강나무 23.36 (5.84\%), 핕배나무 23.21 (5.80\%), 담쟁이덩굴 22.30 (5.57\%), 때죽나무 17.69 (4.42\%) 순으로 높게 나타났다. 교목층에는 상수리나무 25.60, 소사나무 16.95 , 밤나무 13.72 순으로 중요치가 나타 났으며, 아교목층의 중요치는 팥배나무가 20.03으로 가장 높게 나타났고, 상수리나무, 소사나무, 생강나무, 쪽동백나무는 모두 12.31로 나타났다. 관목층의 중요 치는 소사나무 17.46 , 생강나무 9.52, 천선과나무 9.38의 순이었고, 초본층은 담쟁이덩굴의 중요치가 20.26 으로 가장 높게 나타났으며, 천선과나무 4.47, 넉 줄고사리와 물통이 3.91로 각각 나타났다. 소사나무의 중요치는 교목층, 아교목층, 관목층, 초본층 각각
$16.95,12.31,17.46,0.97$ 로 전반적으로 모든 층위에 서 다소 높게 출현하고 있었다. 교목층에는 상수리나 무가 25.60으로 가장 높았으며, 핕배나무는 아교목층, 관목층에서 각각 $20.03,3.17$ 로 나타났고, 담쟁이덩굴 은 관목층, 초본층에서 각각 $2.04,20.26$ 으로 초본층 의 중요치가 가장 높았다(Table 5). 이는 사면하부의 본 식생단위가 다른 식생단위에 비해 교란의 정도가 다소 높다는 것을 반영하고 있는 것으로 사료되었다.

\subsection{5. 식생단위 5(쉬나무군락; 조사구수 2)}

본 식생단위는 종군 2 의 쉬나무, 명아주, 병아리꽃 나무, 줄사철나무, 줄딸기, 장구밥나무의 표징종 또는 식별종 출현에 의해 분류된 쉬나무군락의 단위로 총 2 개소가 조사되었다. 본 식생단위의 입지환경을 볼 때, 평균해발고는 $26 \mathrm{~m}(22 \mathrm{~m}-29 \mathrm{~m})$ 로 5 개의 식생단위 중 에서 가장 낮았으나, 평균경사도는 $45^{\circ}$, 평균암석노출 도 $33 \%(30 \%-35 \%)$ 로 가장 높은 수치를 나타내고 있었다. 교목층의 평균식피율은 $55 \%(30 \%-80 \%)$ 로

Table 6. Importance value of major species at vegetation unit 5

\begin{tabular}{|c|c|c|c|c|c|}
\hline \multicolumn{6}{|c|}{ Layer } \\
\hline Scientific name & Tree & Subtree & Shrub & Herb & Total $(\%)$ \\
\hline Evodia daniellii & 48.72 & 23.72 & 5.44 & 2.71 & $80.59(20.14)$ \\
\hline Robinia pseudoacacia & 25.64 & - & 5.44 & 3.91 & $35.00(8.74)$ \\
\hline Quercus dentate & 25.64 & - & - & 2.56 & $28.20(7.05)$ \\
\hline Carpinus coreana & - & 23.88 & - & 2.56 & $26.44(6.61)$ \\
\hline Pueraria thunbergiana & - & 16.55 & 9.52 & 2.56 & $28.63(7.15)$ \\
\hline Grewia biloba & - & 7.17 & 16.33 & 2.56 & $26.05(6.51)$ \\
\hline Celtis biondii & - & 7.17 & 9.52 & - & $16.69(4.17)$ \\
\hline Prunus persica & - & 7.17 & 5.44 & - & $12.61(3.15)$ \\
\hline Parthenocissus tricuspidata & - & 7.17 & - & 5.12 & $12.28(3.07)$ \\
\hline Tilia amurensis & - & 7.17 & - & - & 7.17(1.79) \\
\hline Euonymus alatus & - & - & 16.33 & - & $16.33(4.08)$ \\
\hline Quercus aliena & - & - & 5.44 & - & 5.44(1.36) \\
\hline Hovenia dulcis & - & - & 5.44 & - & $5.44(1.36)$ \\
\hline Vitis flexuosa & - & - & 5.44 & - & $5.44(1.36)$ \\
\hline Sorbus alnifolia & - & - & 3.91 & - & $3.91(0.98)$ \\
\hline Prunus leveilleana & - & - & 3.91 & - & $3.91(0.98)$ \\
\hline Rhus chinensis & - & - & 3.91 & - & $3.91(0.98)$ \\
\hline Rosa multiflora & - & - & 3.91 & - & $3.91(0.98)$ \\
\hline Euonymus japonica & - & - & - & 5.77 & $5.77(1.44)$ \\
\hline Humulus japonicus & - & - & - & 5.77 & $5.77(1.44)$ \\
\hline Rhodotypos scandens & - & - & - & 5.12 & $5.12(1.28)$ \\
\hline Other 27 species & - & - & - & 61.39 & $61.39(15.38)$ \\
\hline Total & 100 & 100 & 100 & 100 & $400(100.00)$ \\
\hline
\end{tabular}


가장 낮았으며, 평균출현종수는 29 종으로 가장 많이 나 타났지만, 칡, 아까시나무, 청가시덩굴, 담쟁이덩굴, 명 아주 등의 구성종들로 미루어 볼 때, 종다양성은 높지 만 마을 인근에 위치하고 있는 조사지 교란의 원인에 기인된 것으로 사료되었다.

본 식생단위의 중요치는 쉬나무 80.59 (20.14\%), 아 까시나무 $35.00(8.74 \%)$, 칡 $28.63(7.15 \%)$, 떡갈나무 $28.20(7.05 \%)$, 소사나무 $26.44(6.61 \%)$, 장구밥나무 26.05 (6.15\%), 폭나무 16.69 (4.17\%)의 순으로 높게 나타났다. 교목층에는 쉬나무의 중요치가 48.72 , 아까 시나무, 떡갈나무는 모두 25.64 의 순으로 높게 나타났 고, 아교목층은 소사나무 23.88 , 쉬나무 23.72, 칡 16.55 의 순으로 나타났다. 관목층은 장구밥나무, 화살 나무가 모두 16.33 으로 가장 높게 나타났으며, 초본층 에는 사철나무와 환삼덩굴이 5.77 , 담쟁이덩굴이 5.12 의 순으로 나타났다. 쉬나무의 중요치는 교목층, 아교 목층, 관목층, 초본층에 각각 $48.72,3.72,5.44,2.71$ 로 모든 층위에서 높은 중요치 값으로 나타나고 있었 으며, 장구밥나무는 아교목층, 관목층, 초본층 각각 $7.17,16.33,2.56$ 으로 각각 나타났다(Table 6).

\section{3. 환경과의 상관관계}

총 32 개 조사구 식생군락의 입지환경을 분석한 결 과 소사나무군락은 해발 $26 \mathrm{~m}$ 에서 $295 \mathrm{~m}$ 까지 전체적으 로 출현하였고, 마니산 조사지의 경사도는 45 에서 12 까지 나타나고 있었다. 암석노출도는 3에서 $33 \%$ 로 나 타나고 있었으며, 교목층의 수고는 $5 \mathrm{~m}$ 에서 $12 \mathrm{~m}$ 로 능선부의 소사나무는 입지조건의 극심한 환경요인으로 수고가 높지 않은 것으로 나타났다. 각 조사구의 평균

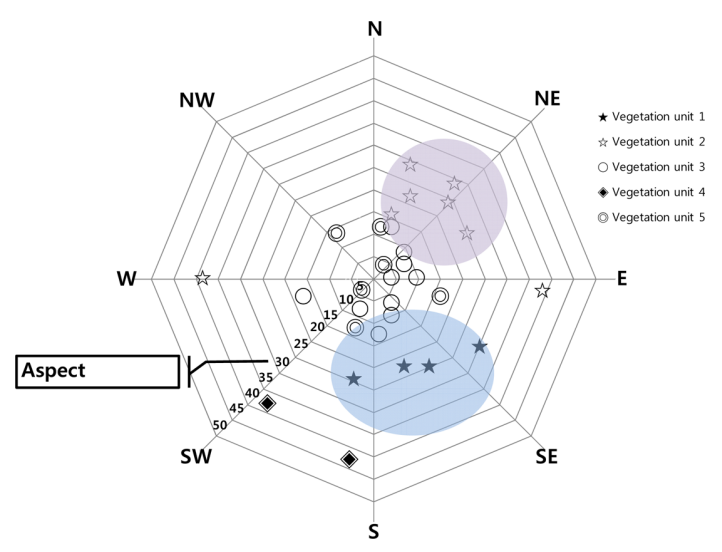

Fig. 3. Relationships between aspect and vegetation units.
출현종수는 20 종으로 나타났으며, 특히 마니산에서 출 현하고 있는 식생유형의 사면별 분포 경향을 살펴보면, 주로 남사면에서 소나무가 많이 분포하는 경향을 보이 고 있었고, 북사면에는 신갈나무가 분포하고 있었는데, 이는 한국 산림의 식물사회학적 분류(Yun, 2011)에서 보고하는 것과 같은 앙상으로 신갈나무는 우리나라의 대표적인 산림군락으로 사면방향분포가 대부분 북사면 에 위치하고 있다는 결과와 비슷한 결과를 나타내고 있었다(Fig. 3).

\section{적 요}

본 연구의 목적은 산림식생에 대한 기본 정보를 확 인하고, 강화도 마니산에있는 산림의 효율적인 관리를 위한 산림식생의 계층구조와 관련된 식생학적 자료를 축적하는 데 있다. 샘플은 2010 년 8월에서 10 월까지 수집된 32 개소의 조사구에 대해 $\mathrm{ZM}$ 학파의 식물사회 학적 분석방법으로 식생군락을 구분하였고, 중요치 분 석을 수행하였다. 식물사회학적 식생분석결과 산림식 생은 여러 종들의 구분에 의해 2 개 군락, 2 개 군, 4 개 소군으로 분류되었고, 복잡한 환경인자들에 의해 결 정되어진 것으로 사료되는 식생유형은 총 5 단위로 나타 났다. 5 개의 식생유형 중 식생단위 1 의 중요치는 소나무 54.31 (18.10\%)로 나타났으며, 신갈나무 39.21 (13.07\%), 식생단위 2 의 서어나무가 $37.29(12.43 \%)$, 신갈나무 89.43 (22.23\%), 진달래 63,525 (14.43\%)로 나타났다. 식생단위 3 에서 때죽나무의 중요치 $53.97(13.50 \%)$, 당 단풍 $33.60(8.40 \%)$, 서어나무 $26.48(6.62 \%)$, 졸참나 무 22.51 (5.64\%)로 나타났으며, 식생단위4에서는 서 어나무 $47.70(11.92 \%)$, 상수리나무 $38.40(9.60 \%)$ 로 나타났고, 식생단위 5 의 쉬나무가 $80.59(20.14 \%)$, 아까 시나무 $35.00(8.74 \%)$, 칡의 중요치가 $28.63(7.15 \%)$, 떡갈나무 $28.20(7.05)$ 의 순으로 중요치가 나타났다. 이는 1997년 강화도의 기후와 산림생태계 현황(Lee, 1997)에서 온대중부림의 생태적 천이는 소나무에서 참 나무류를 거쳐 서어나무류의 순서라는 학설이 거의 입 증되었는데, 강화도 마니산의 산림식생은 천이발달의 중간단계로 보고한 바 있는데, 현재의 산림식생은 소 나무군집, 신갈나무군집, 때죽나무군집, 서어나무군집, 쉬나무군집으로 분류되고, 각 식생단위에서 서어나무 의 중요치가 높게 나타나는 것으로 미루어 인위적, 자 연적 교란이 없는 한 서어나무로의 천이가 진행될 것 
으로 사료된다.

\section{감사의 글}

본 논문은 2013년 차세대 산림시업기술개발 연구사 업단(과제번호:S211313L020110)의 지원에 수행되었습 니다.

\section{REFERENCES}

Braun-Blanquet, J., 1964: Pflanzesoziologie Grundzugeder Vegetationder Vegetation(3). Auf, Springer-Verlang, Wien, N. Y., 865pp.

Cho, H. J., B. C Lee, and J. H. Shin, 2004: Forest vegetation structure and species composition of Baekdudaegan mountain range in South Korea. Journal of Korean Forest Society. 93(5), 331-338. (in Korean with English abstract)

Dierssen, K., 1990: Einfhrung Pflanzensoziologie. AkademieVerlag. Berlin., 241pp.

Ellenberg, H., 1956: Grundlagen der vegetationsgliederung. I. Aufgaben und Methoden der Vegetation skunde. In : Walter, H.(Hrsg.) Einfuhrung in die Phytologie IV. Stuttgart., 136pp.

Harris, L. D., 1984: The fragmented forest: Island biogeography theory and the preservation of biotic diversity, The University of Chicago Press.

Kang, Y. M., 1969: taxonomic study in the vicinity of the reclaimed land in Kanghwa island. Seoul University. Master's Thesis, 408pp.

Kim, J. Y., 2006: Development of the community planting models for the urban green space in the metropolitan area, the middle temperate zones, Korea University of Seoul. Ph. D. Thesis, 283pp.

Kim, Y. H., I. H. Park, and K. J. Cho, 2012: Bird species diversity analysis according to the type of forest vegetation. The Korea Society of Environment Restoration Technology 15(6), 43-52. (in Korean with English abstract)

Kim, W., J. H. Park, and Y. H. Cho, 1999: Effects of fire on forest vegetation in Mt. Samma. Korean Journal of Environment and Ecology 89(99), 145-153. (in Korean with English abstract)

Lee, B. C., and C. W. Yun, 2002: Study on the distribution of forest vegetation communities in Mt. Naeyeon. Journal of Ecology and Field Biology 25(3), 153-161. (in Korean with English abstract)

Lee, B. C., C. W. Yun, J. H. Shin, and J. S. Oh, 2001: Community classification of forest vegetation in Mt. Myeonsan. Journal of Korean Forest Society 90(4), 548557. (in Korean with English abstract)

Lee, D. K., 2000: Sprouting and sprout growth of four Quercus species (Q. mongolica, Q. variabilis, $Q$. acutissima and Q. dentata). Annual Report of Research in Agriculture and Life 4(1), 238-240.

Lee, H. J., B. H, Bae, H. N. Jung, Y. M. Jun, and M. P. Hong, 1999: Forest vegetation and soil environment on Mt. Paekun. Korean Journal of Environment Biology 17(1), 35-50. (in Korean with English abstract)

Lee, J. H., C. W. Yun, and S. C. Hong, 2005: Community and population structure of Berchemia berchemiaefolia. Journal of Korean Forest Society 94(4), 269-276. (in Korean with English abstract)

Lee, K. J., 1997: Status of forest ecosystems and the climate of Ganghwa. World and word. Incheon Catholic University Press. 139-179.

Lee, T. B., 2003: Coloured Flora of Korea. Hyangmunsa. Seoul., 990pp.

Lee, Y. N., 2004: Flora of Korea. Kyohak. Seoul., 1247pp.

Ministry of Environment, 1999: The natural environment of Ganghwa (Mt.Mani). Ministry of Environment, 166pp.

Mucina, L., 1997: Classification of vegetation: Past, present and future. Journal of Vegetation Science 8(6), 751-760.

Oh, S. H., C. W. Yun, K. H. Bae, and S. C. Hong, 1998: A study forest vegetation in Mt. Cheongok, Kyungsangpukdo-by the method of phytosociological studies. Journal of Korean Forest Society 87(1), 27-39. (in Korean with English abstract)

Society of America Foresteres (SAF), 1991: Selection cuts increased natural beauty in two Adirondack forest stands, 419pp.

Shin, J. H., 1995: Biodiversity conservation strategies of forest ecosystems. Journal of Korean Forest Society 84(1), 377-393. (in Korean with English abstract)

Song, J. S., K. S. No, H. S., Jung, Keiichi Ohno, and Tetsuo Mochida, 1999: Phytosociological study of the forest vegetation in the mountainous areas of the northern part, Kyungpook province using the methodology of physiognomy and numerical syntaxonomy. Korean Society of Environment and Ecology 22(5), 241-254. (in Korean with English abstract)

Song, Y. H., and C. W. Yun, 2006: Community type and stand structure of the Korean Pine(Pinus koraiensis) national forest in Seoraksan national park. Korean Society of Environment and Ecology 20(1), 29-40. (in Korean with English abstract).

Walter, H., 1979: Vegetation of the Earth and Ecological Systems of the Geo-biosphere (2nd ed.). Springer-Verlag. New York., 274pp.

Wilcox, B. A., and D. D. Murphy, 1985. Conservation strategy: the effects of fragmentation on extinction. American Nationalist. 125, 879-887.

Yun, C. W., J. H. Shin, H. M. Yang, J. H. Lim, and B. C. Lee, 2011: Phytosociological classification of forest vegetation in Korea. Korea Forest Research Institute. Seoul, 135pp.

http://www.kna.go.kr

http://www.ganghwa.incheon.kr 